\title{
A Comparison Between the Therapeutic Effect of Metformin Alone versus a Combination Therapy with Insulin in Uncontrolled, Non-Adherence Patients with Type 2 Diabetes: Six Months Follow-Up
}

\author{
Anna Paczkowska (1D \\ Karolina Hoffmann ${ }^{2}$ \\ Michał Michalak (D) ${ }^{3}$ \\ Wiesław Bryl $\mathbb{D}^{2}$ \\ Dorota Kopciuch' \\ Tomasz Zaprutko' \\ Piotr Ratajczak' \\ Elżbieta Nowakowska ${ }^{4}$ \\ Krzysztof Kus'

\begin{abstract}
'Department of Pharmacoeconomics and Social Pharmacy, Poznan University of Medical Sciences, Poznań, Poland;

${ }^{2}$ Department of Internal Diseases, Metabolic Disorders and Arterial Hypertension, Poznan University of Medical Sciences, Poznań, Poland;

${ }^{3}$ Department of Computer Science and Statistics, Poznan University of Medical Sciences, Poznań, Poland; ${ }^{4}$ Department of Pharmacology and Toxicology, Institute of Health Sciences, Collegium Medicum, University of Zielona Gora, Zielona Góra, Poland
\end{abstract}

Purpose: The study aimed to compare the metabolic effects of an intensive dose of metformin alone among non-adherence patients with type 2 diabetes versus in combination with insulin among adherence patients.

Methods: The prospective cohort study was carried out on a sample of 140 patients above 18 years old, divided into two groups. The first group $(n=70)$ was recommended metformin monotherapy in an intensive dose of $2-3$ g/day, whereas the second group $(n=70)$ was prescribed metformin (1-2g/day) in combination with insulin. FPG, HbA1c, BMI, blood pressure, TC, TG, HDL-C, LDL-C, creatinine, and eGFR were measured for each patient at baseline and after a follow-up of 6 months of active treatment.

Results: After six months of active treatment using monotherapy with an intensive dose of metformin, only $11.43 \%$ of patients achieved the target levels of HBA1c below $7 \%$. In the group of patients treated using a combination of metformin with insulin, after six months of active treatment, $45.72 \%$ achieved HBA1c levels below $7 \%(\mathrm{p}<0.0001)$. Compared with an intensive dose of metformin alone, the combination of insulin and metformin was associated with improved glycemic control (change of fasting blood glucose: $2.49 \mathrm{mmol} / \mathrm{l}$ vs $1.30 \mathrm{mmol} / \mathrm{l}, \mathrm{p}=0.0016$ ). Metformin use alone, as compared with insulin, was associated with a significant increase in HDL-C $(+0.03 \mathrm{mmol} / \mathrm{l}$ vs $-0.14 \mathrm{mmol} / \mathrm{l}, \mathrm{p}=0.0485)$. Increased baseline obesity and increased baseline glycemia were the factors related to the likelihood of failing to achieve the target levels for $\mathrm{HbAlc}$.

Conclusion: Metformin proved to be more effective in controlling hyperglycemia when combined with insulin therapy. Our study shows how many health benefits loss patients who, despite systematic diabetes education, do not agree to change their treatment in the form of adding a second drug, including insulin.

Keywords: type 2 diabetes, non-adherence, metformin, insulin, effectiveness of the treatment

\section{Introduction}

The pathological processes involved in the origin of diabetes mellitus (DM) type 2 include impaired insulin secretion, defects of insulin action or both, and insulin resistance. ${ }^{1-4}$ Type 2 diabetes accounts for $90 \%$ of all the cases of diabetes mellitus. 
The most significant number of people with diabetes mellitus are between 40 and 59 years old. ${ }^{5-8}$ Today, the first-line treatment of type 2 DM among adults is usually based on metformin. There are several potential actions of metformin with the leading effect which relies on the inhibition of hepatic gluconeogenesis. ${ }^{9,10}$ Many studies conducted to date have shown a positive effect of only metformin therapy on metabolic parameters. ${ }^{11-14}$ It not only improves glycaemic control by enhancing insulin sensitivity in the liver and muscles but also increases insulin receptor tyrosine kinase activity, stimulates glucose transport and glycogen synthesis, and reduces both hepatic gluconeogenesis and glycogenolysis. In addition, metformin has been reported to decrease lipid oxidation and plasma-free fatty acid levels, leading to an inhibition of an overactive Randle cycle. Furthermore, improved metabolic control with metformin does not induce weight gain and may cause weight loss. ${ }^{11-14}$ A significant number of patients with type 2 diabetes cannot achieve tight glycaemic control with oral agents and need to be treated with insulin, either as a single agent or added to an oral regimen. ${ }^{10,15}$ The Diabetes Prevention Program demonstrated that metformin improves $\beta$-cell function and reduces diabetes progression by $31 \%$ over three years in adults with impaired glucose tolerance. ${ }^{16}$ Another study has shown that among adults with newly diagnosed type 2 diabetes, two weeks of intensive insulin therapy improves and maintains the $\beta$-cell function, resulting in prolonged remission from requiring diabetes medication. ${ }^{17}$

Despite an ongoing educational campaign on diabetes and its complications, some patients are still unaware of the dangers posed by metabolic imbalance. They fail to adhere to recommendations, are more worried about undergoing more intense forms of therapy than potential macro and microvascular complications. Non-adherence is defined as "an active process whereby the patient chooses to deviate from the treatment regimen". ${ }^{18}$ Patients may be non-adherent during different stages of diabetes treatment. Consequently, substantial numbers of patients do not benefit optimally from pharmacotherapy, resulting in increased morbidity and mortality and increased social costs. ${ }^{19}$ One study showed that while patients with diabetes who take medication correctly have a $7 \%$ death rate, for those who are non-compliant, the death rate is $12 \% .^{20}$ It's estimated that the rate of non-adherence was between $16.7 \%$ and $80 \%$ among patients suffering from tuberculosis, hypertension, asthma, diabetes, epilepsy, and congestive cardiac failure. ${ }^{21}$ Patient non-adherence is a serious healthcare concern that poses a significant challenge to the successful delivery of healthcare. In scientific databases, there is a shortage of information on comparing treatment efficacy between non-adherence patients with diabetes, who do not agree to polytherapy treatment options versus adherence patients with diabetes. Thus far, the studies conducted reported that the addition of metformin to insulin in patients with poorly controlled type 2 diabetes resulted in improved glycemic control and reduced insulin requirements without side effects. ${ }^{15,22}$

One of the key reasons for conducting this study was to explore the health consequences of refusing treatment as prescribed by the current guidelines. As practitioners, we sometimes face problems with non-adherent patients who, despite our best efforts to explain the benefits of proper therapy, do not want to follow recommendations. In the future, we want to share our results with potential new patients, who might hesitate to decide whether or not to be treated according to the doctor's suggestion.

Thus, the study aimed to compare the metabolic effects of an intensive dose of metformin alone among nonadherence patients with type 2 diabetes versus in combination with insulin among adherence patients. Another objective of the study was to assess predictive factors associated with the likelihood of failing to achieve target levels for $\mathrm{HbA1c}$.

\section{Materials and Methods Study Population}

The prospective, cohort study was conducted at the metabolic disorders clinic in Poland (Poznań city) over the time horizon in question - from 1 January 2019 to 31 December 2019. Based on experiences with less cooperative patients, 140 consecutive outpatients, and inpatients aged between 18 and 80 with the exact duration of diabetes and in a similar state of metabolic imbalance (not achieving target $\mathrm{HbA} 1 \mathrm{c}$ values undercurrent the treatment with $1 \mathrm{~g}$ of metformin daily for six months) were recruited to the study and presented with therapeutic options according to the current Polish Diabetes Association guidelines. $^{10}$

Patients were divided into two groups:

Group 1: Type 2 diabetes mellitus non-adherence patients (who refused to add other oral agents or insulin to metformin, they only consented to an intensive dose of metformin) $(n=70)$ on metformin monotherapy in an intensive dose of 2-3 g/day. 
Group 2: Type 2 diabetes mellitus adherence patients $(n=70)$ on the combined treatment, which consist of metformin (1-2 g/day) and insulin.

Therapeutic options were fully discussed with patients during the course of several medical consultations. Patients who consequently refused to intensify the therapy, heedless of arguments presented by medical professionals, continued the treatment they were on to date. It must be emphasized that patients from the first group refused polytherapy (intensify treatment: add another oral agent, GLP-1 receptor agonist, or basal insulin), which may have failed to achieve the desired therapeutic effects. The reasons for the decisions were different, including the drug's price or fear of insulin therapy. Those patients adhered to treatment options entailing an intensive dose of metformin. Their attending physician decided to include a patient in the study. Before the survey, each eligible study subject was informed about the study objective and conditions and gave their written informed consent to participate in the study. The idea of the study, as well as its inclusion and exclusion criteria, were developed during long-lasting observation of non-adherent diabetic patients admitted to a hospital or consulted at an outpatient clinic. For the study, we recruited subjects who were consequently resistant to rational arguments for a necessary treatment change and compared them with an appropriate group of patients who agreed to the intensification of therapy as suggested by a doctor. We aimed to have our own evidence for potential new patients who might hesitate to decide whether or not to be treated according to the doctor's suggestion. All patients who qualified for the study had a baseline $\mathrm{HbAlc}$ of $\geq 7 \%$. The main inclusion criteria were: age of the patients (18-80 years old), HbAlc $\geq 7 \%$, and patient's consent to participation in the study. The main exclusion criteria were: ketoacidosis, acute myocardial infarction (AMI), congestive heart failure (CHF), renal and liver failure, being pregnant and breastfeeding, the lack of patient consent to participate in the study. The study protocol was approved by the Ethics Committee of the Poznan University of Medical Sciences (No. 35/20). This study was conducted in accordance with the Declaration of Helsinki.

\section{Study Technique}

During the follow-up, six months of active treatment, each subject successively increased the metformin dose: in group 1 - from $1 \mathrm{~g} /$ day up to $3 \mathrm{~g} /$ day; in group 2 - from $1 \mathrm{~g}$ /day up to $2 \mathrm{~g}$ /day, if tolerated. The mean daily dose of metformin in group 1 was $2.5 \mathrm{~g}$ /day and $1.5 \mathrm{~g}$ /day in group 2. Patients from the group treated with a combination of metformin and insulin were additionally treated with insulin. Patients were given insulin at a starting dose of $0.1-0.2 \mathrm{um} / \mathrm{kg}$.b.w. or 10 um of sustained-release insulin (NPH insulin or long-acting analog). Based on self-monitoring results, doses were increased until a full balance was achieved. According to PDA 2021 guidelines, ${ }^{10}$ in cases with basal insulin requirements of $>0.3-0.5 \mathrm{u} / \mathrm{kg}$ per day and continued lack of glycaemic balance, either blends of short-acting and longacting insulin were used, or injections of short-acting insulin/fast-acting analog for 1-3 meals ("basal-plus," intensive insulin therapy) were added to sustained-acting insulin administered 1 or 2 times a day.

At the beginning and the end of the follow-up study, fasting blood samples were drawn, a physical examination was carried out, and updated patient's medical records were analyzed. Fasting plasma glucose (FPG), glycated hemoglobin (HbA1c), lipid profile: total cholesterol (TC), triglyceride (TG), high-density lipoprotein (HDL-C), low-density lipoprotein (LDL-C), body mass index, diastolic and systolic blood pressure, and renal function parameters - creatinine and estimated glomerular filtration rate eGFR were all assessed in the whole study group at baseline and after a follow-up of 6 months active treatment. All participants had blood collected from a forearm vein in serum-separated tubes (without using an anticoagulant). Coagulated blood was left to clot at room temperature for $30 \mathrm{~min}$ and then centrifuged for $15 \mathrm{~min}$ at $2000 \mathrm{rpm}$ at $4^{\circ} \mathrm{C}$. Then the supernatant fluid was separated. Serum samples were stored at $-20^{\circ} \mathrm{C}$ for no longer than 2-3 days. Blood samples were collected after an overnight fast and after $30 \mathrm{~min}$ in the supine position. Laboratory tests were performed in hospital laboratories using specific Atellica Solution (Siemens) equipment. Plasma glucose levels were determined using a Hexokinase method. ${ }^{23}$ Glycated hemoglobin (HbAlc) was measured by high-performance liquid chromatography and by an immunoturbidimetric method. ${ }^{24} \mathrm{TC}$, LDL-C, HDL-C, and TG were measured with commercially available assay kits (Dimension ${ }^{\circledR}$, Siemens, Germany). Highdensity lipoprotein cholesterol- precipitated using dextran sulfate, was measured enzymatically, low-density lipoprotein cholesterol- was calculated using the Friedewald equation (LDL-Ch $=$ TCh- $(\mathrm{TG} / 5)-\mathrm{HDL}-\mathrm{Ch}^{25}$ Moreover, blood pressure, weight, height, and waist and hip circumferences were measured. BMI $(\mathrm{kg} / \mathrm{m} 2)$ was calculated for each patient in each group at baseline and after a follow-up of 6 months of active treatment by a nurse specialized in diabetes care. Patients were weighed wearing underclothes. The initial and follow-up blood pressure measurement was taken on both arms. During each visit (baseline and follow-up), two blood pressure 
measurements were made over a 3-minute interval. The mean blood pressure value from the two measurements was used for data analysis. We used a mercury sphygmomanometer with several cuffs, depending on the size of the subject's arm. ${ }^{26}$

The patient's demographic data (age, gender, education), information on the progress of the disease (presence of comorbid disorders), and control were also collected at baseline from an analysis of the patient's medical records.

\section{Statistical Analysis}

The quantitative parameters were presented using mean value, median, and standard deviation. Categorical data were presented as counts and percentages. The results between the analysed groups were compared using the Student's $t$-test. Where data did not follow the normal distribution (Shapiro-Wilks test), the comparison was performed using the Mann-Whitney test. More than two groups were compared using the Kruskal-Wallis test with the post hoc Dunn's test. The Chi-square test for independence was used to analyze categorical data. According to the planned study design, the significance of the effects of metformin alone, as compared with the insulin combination, on the quantitative endpoints (Fasting blood glucose (FBG), glycated hemoglobin (HbA1c), lipid profile, body mass index, diastolic and systolic blood pressure, and creatinine level) was assessed by analyzing the final value, adjusted for the baseline value using ANCOVA. A logistic regression analysis was performed to determine the predictive factors associated with the likelihood of failing to achieve the target levels for HbA1c.

The analysis was performed with the use of the TIBCO Software Inc (2017) statistical package. Statistical (data analysis software system), version 13. http://statistica.io. All tests were considered significant at $\mathrm{p}<0.05$.

\section{Results}

\section{Study Group Characteristics}

The study groups numbered 140 patients (70 patients received metformin in monotherapy- $M$ and 70 patients received metformin in combination with insulin- MI). The studied groups of patients did not differ significantly in terms of gender. Men predominated in both study groups $(58.57 \%$ in the group of patients who received metformin in monotherapy and $61.43 \%$ in the group of patients who received metformin in combination with insulin). The studied groups of patients at baseline differed statistically significantly in terms of low-density
lipoprotein-LDL level $(2.93 \pm 0.90-\mathrm{M}$ vs $2.66 \pm 1.20$ MI, $\mathrm{p}=0.039)$. There were no statistically significant differences between the groups in terms of the analyzed parameters (Table 1).

Table I Baseline Demographic and Clinical Characteristics of Patients with Uncontrolled Glycaemic Profile Treated by Metformin in Monotherapy and in Combination with Insulin, $n=\mid 40$

\begin{tabular}{|c|c|c|}
\hline & Metformin & $\begin{array}{l}\text { Metformin } \\
\text { Plus Insulin }\end{array}$ \\
\hline Group size $n$ & 70 & 70 \\
\hline Female $\mathrm{n}(\%)$ & $29(4 \mid .43)$ & $\begin{array}{l}27(38.57) \\
\quad \text { NS }\end{array}$ \\
\hline Male n (\%) & $4 \mid(58.57)$ & $\begin{array}{c}43(61.43) \\
\text { NS }\end{array}$ \\
\hline Age (mean $\pm S D$ ) & $55.11 \pm 11.93$ & $\begin{array}{c}54.91 \pm 11.33 \\
\text { NS }\end{array}$ \\
\hline $\begin{array}{l}\text { Duration of the disease (years) } \\
\text { (mean } \pm \mathrm{SD} \text { ) }\end{array}$ & $3.48 \pm 5.48$ & $\begin{array}{c}3.33 \pm 5.12 \\
\text { NS }\end{array}$ \\
\hline Body mass index $\left(\mathrm{kg} / \mathrm{m}^{2}\right)$ & $4 I .34(9.7 I)$ & $\begin{array}{l}40.39(6.65) \\
\text { NS }\end{array}$ \\
\hline $\begin{array}{l}\mathrm{HbAlc}(\%) \\
(\text { mean } \pm \mathrm{SD})\end{array}$ & $7.5 \pm 0.2$ & $\begin{array}{c}7.4 \pm 0.3 \\
\text { NS }\end{array}$ \\
\hline $\begin{array}{l}\text { Fasting plasma glucose }(\mathrm{FPG}) \\
(\mathrm{mmol} / \mathrm{L})(\text { mean } \pm \mathrm{SD})\end{array}$ & $7.87 \pm 1.14$ & $\begin{array}{l}7.90 \pm 1.22 \\
\text { NS }\end{array}$ \\
\hline $\begin{array}{l}\text { Systolic blood pressure }[\mathrm{mm} / \\
\mathrm{Hg}] \text { (mean } \pm \mathrm{SD} \text { ) }\end{array}$ & $134.48 \pm 18.63$ & $\begin{array}{c}134.20 \pm 2.53 \\
\text { NS }\end{array}$ \\
\hline $\begin{array}{l}\text { Diastolic blood pressure [mm/ } \\
\mathrm{Hg}](\text { mean } \pm \mathrm{SD})\end{array}$ & $82.95 \pm 11.74$ & $\begin{array}{c}83.62 \pm 15.19 \\
\text { NS }\end{array}$ \\
\hline $\begin{array}{l}\text { Creatinine [umol/L] (mean } \pm \\
\mathrm{SD} \text { ) }\end{array}$ & $83.91 \pm 20.70$ & $\begin{array}{c}83.66 \pm 22.65 \\
\text { NS }\end{array}$ \\
\hline $\begin{array}{l}\text { eGFR }[\mathrm{mL} / \mathrm{min}] \\
\text { GI [GFR } \geq 90] \text { (\%) } \\
\text { G2 [GFR: 60-89] (\%) }\end{array}$ & $\begin{array}{l}43.59 \\
56.41\end{array}$ & $\begin{array}{c}44.28 \\
55.72 \\
\text { NS }\end{array}$ \\
\hline $\begin{array}{l}\text { Total cholesterol- TC }[\mathrm{mmol} / \mathrm{L}] \\
(\text { mean } \pm \mathrm{SD})\end{array}$ & $4.88 \pm 1.05$ & $\begin{array}{l}4.90 \pm 1.71 \\
\text { NS }\end{array}$ \\
\hline $\begin{array}{l}\text { Triglyceride- TG }[\mathrm{mmol} / \mathrm{L}] \\
(\text { mean } \pm \mathrm{SD})\end{array}$ & $2.12 \pm 1.00$ & $\begin{array}{l}2.65 \pm 2.87 \\
\text { NS }\end{array}$ \\
\hline $\begin{array}{l}\text { High density lipoprotein-HDL } \\
{[\mathrm{mmol} / \mathrm{L}](\text { mean } \pm \mathrm{SD})}\end{array}$ & $1.15 \pm 0.30$ & $\begin{array}{l}1.22 \pm 0.42 \\
\quad \text { NS }\end{array}$ \\
\hline $\begin{array}{l}\text { Low density lipoprotein-LDL } \\
[\mathrm{mmol} / \mathrm{L}] \text { (mean } \pm \mathrm{SD})\end{array}$ & $2.93 \pm 0.90$ & $\begin{array}{c}2.66 \pm 1.20 \\
p=0.0391\end{array}$ \\
\hline
\end{tabular}

Note: $(p>0.05)$.

Abbreviations: SD, standard deviation; NS, no significance. 


\section{A Comparison Between the Therapeutic} Effect of Metformin Alone versus

\section{a Combination Therapy with Insulin Glycaemic Control}

The performed statistical analysis of data using the post hoc test revealed that after the six months follow-up active treatment, the level of $\mathrm{HbAlc}$ significantly decreased from $7.5 \pm 0.2 \%$ to $7.2 \pm 1.1$ (mean decrease- $0.7 \pm 1.7 \%$, $\mathrm{p}<0.0001)$ in the intensive metformin dose group and showed a highly significant decrease from $7.4 \pm 0.6 \%$ to $6.8 \pm 1.3 \%$ (mean decrease- $1.1 \pm 2.3, \mathrm{p}<0.001$ ) in the metformin and insulin-treated patients. FBG decreased significantly more in the metformin plus insulin group than in the intensive dose of metformin alone group. The mean FBG level decreased from $7.87 \pm 1.14$ to $6.89 \pm 1.21$ $\mathrm{mmol} / \mathrm{L}$ (mean change- $1.30 \pm 2.10 \mathrm{mmol} / \mathrm{L}, \mathrm{p}<0.0001$ ) in the only metformin group and from $7.90 \pm 1.22$ to $5.35 \pm$ $2.56 \mathrm{mmol} / \mathrm{L}$ (mean change- $2.49 \pm 2.28, \mathrm{p}<0.0001$ ) in the metformin and insulin group (Table 2). No episodes of clinically overt or silent hypoglycemia were found in either group.

\section{Body Mass Index}

In both groups of patients, the body mass index after six months of active treatment showed a highly significant decrease of $5.27 \pm 11.95 \mathrm{~kg} / \mathrm{m} 2$ in the metformin alone group and by $3.21 \pm 7.86 \mathrm{~kg} / \mathrm{m} 2$ in the metformin plus insulin group $(\mathrm{p}<0.0001)$ (Table 2$)$.

\section{Blood Pressure}

A significant decrease in systolic blood pressure values in both groups was observed. The mean change in systolic blood pressure values in the only metformin group was

Table 2 Comparison Between the Therapeutic Effect of Metformin Alone versus Combination with Insulin in Uncontrolled Polish Patients with Type 2 Diabetes $n=140$

\begin{tabular}{|c|c|c|c|c|c|c|c|}
\hline \multirow[t]{2}{*}{ Outcome Parameters } & \multicolumn{2}{|c|}{ Baseline } & \multicolumn{2}{|c|}{ Follow-Up } & \multicolumn{2}{|c|}{ Change } & \multirow[t]{2}{*}{ P-value } \\
\hline & $\begin{array}{l}\text { Metformin } \\
\text { Alone }\end{array}$ & $\begin{array}{l}\text { Metformin } \\
\text { Plus Insulin }\end{array}$ & $\begin{array}{l}\text { Metformin } \\
\text { Alone }\end{array}$ & $\begin{array}{l}\text { Metformin } \\
\text { Plus Insulin }\end{array}$ & $\begin{array}{l}\text { Metformin } \\
\text { Alone }\end{array}$ & $\begin{array}{l}\text { Metformin } \\
\text { Plus Insulin }\end{array}$ & \\
\hline HbAlc (\%) (mean \pm SD) & $7.5 \pm 0.2$ & $\begin{array}{l}7.4 \pm 0.3 \\
\text { NS }\end{array}$ & $7.2 \pm 1.1$ & $\begin{array}{l}6.8 \pm 1.3 \\
p=0.0214\end{array}$ & $\begin{array}{l}0.7 \pm 1.7 \\
p<0.0001\end{array}$ & $\begin{array}{l}1.1 \pm 2.3 \\
p<0.001\end{array}$ & 0.2492 \\
\hline $\begin{array}{l}\text { Fasting plasma glucose (FPG) } \\
(\mathrm{mmol} / \mathrm{L})(\text { mean } \pm \mathrm{SD})\end{array}$ & $7.87 \pm 1.14$ & $\begin{array}{l}7.90 \pm 1.22 \\
\text { NS }\end{array}$ & $6.89 \pm 1.21$ & $\begin{array}{l}5.35 \pm 2.56 \\
p<0.000 I\end{array}$ & $\begin{array}{l}1.30 \pm 2.10 \\
p<0.0001\end{array}$ & $\begin{array}{c}2.49 \pm 2.28 \\
p<0.000 I\end{array}$ & 0.0016 \\
\hline $\begin{array}{l}\text { Total cholesterol- TC }[\mathrm{mmol} / \mathrm{L}] \\
(\text { mean } \pm \text { SD })\end{array}$ & $4.88 \pm 1.05$ & $\begin{array}{l}4.90 \pm 1.71 \\
\text { NS }\end{array}$ & $4.46 \pm 0.89$ & $\begin{array}{l}4.60 \pm 1.45 \\
\text { NS }\end{array}$ & $\begin{array}{l}0.75 \pm 1.49 \\
p<0.0001\end{array}$ & $\begin{array}{l}0.66 \pm 1.75 \\
P=0.0128\end{array}$ & 0.7437 \\
\hline $\begin{array}{l}\text { Triglyceride- TG }[\mathrm{mmol} / \mathrm{L}] \text { (mean } \pm \\
\text { SD) }\end{array}$ & $2.12 \pm 1.00$ & $\begin{array}{l}2.65 \pm 2.87 \\
\text { NS }\end{array}$ & $1.71 \pm 0.79$ & $\begin{array}{l}1.93 \pm 1.08 \\
\text { NS }\end{array}$ & $\begin{array}{l}0.53 \pm 1.10 \\
p<0.0001\end{array}$ & $\begin{array}{c}0.86 \pm 2.92 \\
\text { NS }\end{array}$ & 0.3778 \\
\hline $\begin{array}{l}\text { High density lipoprotein-HDL } \\
{[\mathrm{mmol} / \mathrm{L}] \text { (mean } \pm \text { SD) }}\end{array}$ & $1.15 \pm 0.30$ & $\begin{array}{l}1.22 \pm 0.42 \\
\text { NS }\end{array}$ & $1.27 \pm 0.29$ & $\begin{array}{c}1.17 \pm 0.28 \\
p=0.0398\end{array}$ & $\begin{array}{c}-0.03 \pm 0.49 \\
p<0.0001\end{array}$ & $\begin{array}{l}0.14 \pm 0.52 \\
\text { NS }\end{array}$ & 0.0485 \\
\hline $\begin{array}{l}\text { Low density lipoprotein-LDL [mmol/ } \\
\text { L] (mean } \pm \text { SD) }\end{array}$ & $2.93 \pm 0.90$ & $\begin{array}{c}2.66 \pm 1.20 \\
p=0.0391\end{array}$ & $2.54 \pm 0.78$ & $\begin{array}{l}2.58 \pm 1.11 \\
\text { NS }\end{array}$ & $\begin{array}{l}0.53 \pm 1.03 \\
p<0.0001\end{array}$ & $\begin{array}{l}0.34 \pm 0.79 \\
\text { NS }\end{array}$ & 0.2228 \\
\hline Body mass index $\left(\mathrm{kg} / \mathrm{m}^{2}\right)$ & $41.34 \pm 9.71$ & $\begin{array}{l}38.39 \pm 6.65 \\
\text { NS }\end{array}$ & $38.25 \pm 9.64$ & $\begin{array}{l}37.02 \pm 7.30 \\
\text { NS }\end{array}$ & $\begin{array}{l}5.27 \pm 11.95 \\
p<0.0001\end{array}$ & $\begin{array}{l}3.21 \pm 7.86 \\
p<0.0001\end{array}$ & 0.2303 \\
\hline $\begin{array}{l}\text { Systolic blood pressure }[\mathrm{mm} / \mathrm{Hg}] \\
\text { (mean } \pm \text { SD) }\end{array}$ & $\begin{array}{l}134.48 \pm \\
18.63\end{array}$ & $\begin{array}{l}134.20 \pm 2.53 \\
\text { NS }\end{array}$ & $\begin{array}{c}131.56 \pm \\
13.24\end{array}$ & $\begin{array}{c}128.95 \pm 14.78 \\
\text { NS }\end{array}$ & $\begin{array}{c}2.95 \pm 12.10 \\
p=0.0429\end{array}$ & $\begin{array}{c}5.25 \pm 12.99 \\
p=0.0083\end{array}$ & 0.2803 \\
\hline $\begin{array}{l}\text { Diastolic blood pressure }[\mathrm{mm} / \mathrm{Hg}] \\
\text { (mean } \pm \text { SD) }\end{array}$ & $\begin{array}{c}82.95 \pm \\
11.74\end{array}$ & $\begin{array}{c}83.62 \pm 15.19 \\
\text { NS }\end{array}$ & $82.19 \pm 9.27$ & $\begin{array}{l}81.50 \pm 10.51 \\
\text { NS }\end{array}$ & $\begin{array}{l}0.77 \pm 6.79 \\
\text { NS }\end{array}$ & $\begin{array}{l}2.12 \pm 7.24 \\
\text { NS }\end{array}$ & 0.2571 \\
\hline Creatinine $[$ umol/L] $($ mean \pm SD) & $\begin{array}{c}83.91 \pm \\
20.70\end{array}$ & $\begin{array}{c}83.66 \pm 22.65 \\
\text { NS }\end{array}$ & $\begin{array}{c}80.87 \pm \\
20.46\end{array}$ & $\begin{array}{c}79.65 \pm 29.47 ? \\
\text { NS }\end{array}$ & $\begin{array}{l}7.57 \pm 28.12 \\
\text { NS }\end{array}$ & $\begin{array}{c}8.66 \pm 27.03 \\
\text { NS }\end{array}$ & 0.8155 \\
\hline $\begin{array}{l}\text { eGFR }[\mathrm{mL} / \mathrm{min}]: \\
\text { GI }[\mathrm{GFR} \geq 90] \text { (\%) }\end{array}$ & 43.59 & $\begin{array}{l}44.28 \\
\text { NS }\end{array}$ & 47.76 & $\begin{array}{l}39.98 \\
\text { NS }\end{array}$ & $\begin{array}{l}-4.17 \\
\text { NS }\end{array}$ & $\begin{array}{l}4.30 \\
\text { NS }\end{array}$ & 0.9178 \\
\hline G2 [GFR: 60-89] (\%) & 56.41 & $\begin{array}{l}55.72 \\
\text { NS }\end{array}$ & 52.24 & $\begin{array}{c}60.02 \\
\text { NS }\end{array}$ & $\begin{array}{l}4.20 \\
\text { NS }\end{array}$ & $\begin{array}{l}-4.30 \\
\text { NS }\end{array}$ & 0.6778 \\
\hline
\end{tabular}


$2.95 \pm 12.10 \mathrm{mmHg}, \mathrm{p}=0.0429$, while in the metformin and insulin group, it was $5.25 \pm 12.99 \mathrm{mmHg}, \mathrm{p}=0.0083$ ). On the other hand, statistical analysis showed no significant change in both groups' diastolic blood pressure values (Table 2).

\section{Lipid Profile}

In the intensive dose of only metformin group, a significant change was found with regard to total cholesterol level (mean decrease: $0.75 \pm 1.49, \mathrm{p}<0.0001$ ), triglyceride levels (mean reduction: $0.53 \pm 1.10$, $\mathrm{p}<0.0001$ ), and low-density lipoprotein levels (mean decrease: $0.53 \pm 1.03, \mathrm{p}<0.0001)$. Analysis of highdensity lipoprotein levels indicated a significant increase observed in subjects on metformin monotherapy (mean increase: $-0.03 \pm 0.49, \mathrm{p}<0.0001)$. A significant change was observed in the metformin plus insulin group only concerning total cholesterol levels (mean decrease: $0.66 \pm$ $1.75, \mathrm{p}=0.0128)$ (Table 2).

\section{Renal Function}

A statistical analysis of the two treated groups showed no significant changes among renal parameters: creatinine level and estimated glomerular filtration rate.

\section{The Effectiveness of the Applied Pharmacotherapy}

After six months of active treatment using monotherapy with an intensive dose of metformin, only $11.43 \%$ of patients achieved the target levels of HBA1c below 7\%. In the group of patients treated using a combination of metformin with insulin, after six months of active treatment, 45.72\% achieved HBA1c levels below 7\%. The observed difference was statistically significant $(\mathrm{p}<0.0001)$.

Statistical analysis of data using the Mann-Whitney test revealed a significant change in the level of fasting blood glucose (FBG) for subjects on combined treatment compared to patients treated with an intensive dose of metformin $(\mathrm{p}=0.0016)$. On the other hand, a significant change in high-density lipoprotein (HDL) concentration was noted in patients treated with metformin alone compared to subjects on combined treatment $(\mathrm{p}=0.0485)$. The analysis revealed no significant change in terms of other analysed outcome parameters between the groups of patients.

\section{Multiple Logistic Regression Analysis of Predictive Factors}

Table 3 shows the results of a multiple logistic regression analysis of the assessment of predictive factors associated with the likelihood of failing to achieve target levels for $\mathrm{HbAlc}$. In this multiple analysis, increased baseline obesity and increased baseline glycemia were all significantly associated with the likelihood of requiring multiple therapies. There were no significant associations with age, gender differences, nor plasma triglycerides.

\section{Discussion}

One of the main goals of treating type 2 diabetes mellitus patients is to produce near-normal glucose levels to prevent the development of diabetic complications. The significant morbidity and mortality of diabetic patients are connected with minor and macrovascular consequences of the disease. ${ }^{27,28}$ Many epidemiological studies have shown that lowering the fasting plasma glucose level to less than $7.8 \mathrm{mmol} / \mathrm{L}$ decreases the risk of developing microvascular complications. ${ }^{29}$ Other studies confirmed that the efficacy treated group of patients with glycosylated hemoglobin levels of $7 \%$ had $25 \%$ less incidence of microvascular endpoints than those with $\mathrm{HbAlc}$ levels of $7.9 \%{ }^{30}$ However, the best way to achieve tight glycaemic control is not clear. Among oral antihyperglycemic agents, metformin is usually the first-line drug for the treatment of type 2 diabetes mellitus. ${ }^{10}$

Nevertheless, a significant number of patients with type 2 diabetes cannot achieve tight glycaemic control with oral agents and need to be treated with insulin, either as a single agent or added to an oral regimen. ${ }^{15,27}$ Literature data indicate that by three years after diagnosis of diabetes, approximately $50 \%$ of patients will need more than one

Table 3 Multiple Logistic Regression Analysis of Predictive Factors in Uncontrolled Polish Patients with Type 2 Diabetes n=140

\begin{tabular}{|l|c|c|}
\hline & \multicolumn{2}{|c|}{ HbAlc > 7\% } \\
\hline Variable & $\begin{array}{c}\text { Odds Ratio } \\
(95 \% ~ C I)\end{array}$ & P value \\
\hline Age per 10 y & $1.59(0.45-5.5 \mathrm{I}$ & 0.4658 \\
Gender & $0.96(0.27-3.46)$ & 0.9598 \\
Fasting plasma glucose per $2 \mathrm{mmol} / \mathrm{L}$ & $2.06(1.21-3.54)$ & 0.0079 \\
Body mass index per $5 \mathrm{~kg} / \mathrm{m}^{2}$ & $4.07(1.18-14.03)$ & 0.0262 \\
Plasma triglyceride per I $\mathrm{mmol} / \mathrm{L}$ & $2.31(0.56-9.46)$ & 0.2434 \\
\hline
\end{tabular}


pharmacological agent due to the failure of monotherapy with sulfonylurea, metformin, or insulin to achieve tight glycaemic control. By nine years following a diagnosis, approximately $75 \%$ of patients will need multiple therapies to achieve $\mathrm{HbA} 1 \mathrm{c}$ levels below 7\%. ${ }^{27,31}$

Completed studies reveal that polytherapy, which relies on a combination of metformin and insulin, delivers a significantly higher decrease in the level of fasting plasma glucose and better $\mathrm{HbA1c}$ control compared with metformin-only therapy. After six months of active treatment using monotherapy with an intensive dose of metformin only, $11.43 \%$ of patients achieved the target levels of HBA1c below 7\%, whereas, in the group of patients treated by a combination of metformin with insulin, $45.72 \%$ achieved HBA1c levels below 7\%. The obtained results are consistent with the well-documented fact that there is a synergy between the anti-hyperglycemic drugs used. ${ }^{32}$ The intensification of metformin monotherapy by adding insulin is a beneficial therapeutic option for poorly controlled hyperglycemia. ${ }^{33}$

Results of performed clinical trials have shown that combined treatment with insulin and metformin improves glycaemic control more significantly than the escalation of dosages of one drug. The obtained results are in line with studies performed by Menesi et al, aiming to analyze the effects of metformin monotherapy and combined treatment with metformin and insulin in the presence of simvastatin on glycaemic and lipid parameters. ${ }^{1}$ It was observed that the whole study group had a satisfied glycaemic control with a significant decrease in $\mathrm{HbAc1}$ noted in subjects on the combination of metformin and insulin. The authors concluded that the beneficial effect of metformin in controlling hyperglycemia was enhanced by insulin without serious complications. This statement is also confirmed by results obtained by Fonseca et al. ${ }^{34}$ Findings confirmed that adding insulin glargine to metformin monotherapy early in the treatment may provide efficacy/safety benefits in superior $\mathrm{HbAlc}$ level reductions after 24 weeks of active treatment. The authors postulated that this might reflect an earlier treatment for the disease and supports the inclusion of insulin as a second step in the American Diabetes Association/European Association for the Study of Diabetes treatment algorithm. Results conducted by Wulffele et al also revealed that the combination of insulin and metformin delivers superior glycaemic control compared to monotherapy based on insulin therapy alone. ${ }^{15}$ Findings showed that in type 2 diabetes mellitus, multiple therapies based on a combination of metformin with insulin are associated with improved glycaemic control, reduced insulin requirement, less weight gain, and a small decrease in LDL cholesterol levels. Our findings clearly show that the combination therapy is beneficial for patients with non-insulin-dependent type 2 diabetes mellitus, for whom metformin therapy proved insufficient, and in accordance with PDA 2021 guidelines, they have to be moved to stage 2 (non-insulin combined therapy) or even to stage 3 of diabetes treatment, ie, simple insulin therapy (basal insulin), and ultimately, if the therapeutic goal is not achieved, to the stage 4 (combined insulin therapy). ${ }^{10}$

This study aimed to compare the efficacy of metformin alone and in combination with the lipid concentrations in patients with DM. In the only metformin group, a significant change was found with regard to TC, TG, LDL-C, and HDL. In the group with combined treatment, a significant difference was observed only in relation to total cholesterol levels. The obtained results are in line with scientific data. ${ }^{11-14}$

Whereas the observed worse effects for the combination of metformin and insulin on the lipid profile may result from the improvement of glycaemic control achieved by both drugs regimen what causes additional benefit for lipid profile. In studies performed by Menesi et al, there was no significant lowering of serum lipids in metformin treated and metformin plus insulin treated groups. ${ }^{1}$ In studies conducted by Wulffele et al the insulin and metformin combination after 16 weeks of treatment was associated with improved glycaemic control, reduced weight gain and decreased plasma LDL cholesterol. ${ }^{15}$ Other studies evaluated the effects of metformin and insulin combinations on glycaemic control, lipid profile, and arterial blood pressure for patients with type 2 diabetes with metabolic syndrome during six months follow up and have shown significantly improved glycaemic control (14\% of patients reaching HbAlc levels of up to $7 \%$, and $53 \%$ reaching values of up to $8 \%$ ). A statistically significant reduction of total cholesterol, BMI, and waist circumference was also identified. The reduction of total cholesterol occurred independently of the reduction of $\mathrm{HbAlc}$ and BMI, and the reduction of BMI and waist circumference did not interfere with the HbAlc improvement. No changes were detected in HDL cholesterol or blood pressure. ${ }^{35}$

In our study, we also detected a significant reduction in body mass index after six months of treatment among patients treated with the intensive dose of only metformin and also in combination with insulin. 
The reduction body mass index was greater for the only metformin alone compared to the combination with insulin $(5.27 \mathrm{~kg} / \mathrm{m} 2$ vs $3.21 \mathrm{~kg} / \mathrm{m} 2)$. Nevertheless, the observed differences were not statistically significant. The obtained results are in line with other studies confirming that metformin alone and in combination with insulin leads to a decrease the body mass index. ${ }^{15,36}$ Some specialists claimed that a decreased food intake caused by is the primary weight loss mechanism. Although the effect of metformin on appetite is likely to be multifactorial, changes in hypothalamic physiology, including leptin and insulin sensitivity, have been documented. In addition, novel work on obesity highlights the gastrointestinal physiology and circadian rhythm changes caused by metformin as affecting the food intake and the regulation of fat oxidation and storage in the liver, skeletal muscle, and adipose tissue. ${ }^{37}$

A significant decrease of systolic blood pressure in both groups of patients that did not differ between the groups was observed in the performed studies. The obtained results are in line with other studies. In the double-blind, cross-over, randomized studies performed by Giugliano et al after 12 weeks of treatment using only metformin among obese, hypertensive women, a significant decrease of following parameters were observed: fasting glucose, $\mathrm{HbAlc}$, fasting and glucose-stimulated insulin, blood pressure and left ventricular mass, cholesterol, triglycerides, and fibrinogen. ${ }^{38}$ On the other hand, high-density lipoprotein cholesterol increased. The improvement in glucose metabolism resulted from an increased sensitivity to insulin.

Moreover, the clinically significant effect of metformin use on the reduction of systolic blood pressure was confirmed by a meta-analysis conducted by Long et al, which included twenty-eight studies from 26 articles consisting of 4113 participants. ${ }^{39}$ The pooled results showed that metformin had a significant effect on SBP but not on DBP. In subgroup analysis, it was found that the effect of metformin on SBP was significant in patients with impaired glucose tolerance or obesity. A significant reduction in blood pressure was also observed for the combination of metformin with insulin in studies performed by Giugliano et al. ${ }^{40}$ Based on the obtained results, the authors concluded that combining metformin with insulin for obese, poorly controlled patients with type 2 diabetes may represent a safe strategy to achieve better glycaemic control with a reduction in certain metabolic risk factors associated with the increased incidence of cardiovascular disease for diabetes mellitus.
The logistic regression analysis performed as part of this study revealed that increased baseline obesity and increased baseline glycemia were all significantly associated with the likelihood of failing to achieve the target levels for HbAlc. The obtained results are in line with studies performed by Turner et al. ${ }^{27}$ Predictive factors associated with the likelihood of failing to achieve the target levels for $\mathrm{HbAlc}$ were: younger age, initial severity of diabetes, and degrees of obesity. In the studies performed by Khattab et al, factors associated with poor glycaemic control among patients with type 2 diabetes were: longer duration of diabetes and not adhering to diabetes self-care management behaviors. ${ }^{41}$ Other studies revealed that factors related to the failure to reach the target levels for $\mathrm{HbAlc}$ include: race, age, poorer baseline glucose control, insulin use, severe hypoglycemia, and weight gain. ${ }^{42}$

However, our study has some limitations. The most important limitation is the fact that the study sample was recruited from a single center. The study population was relatively small $(\mathrm{n}=140)$, and generalizations may prove difficult. It would be very interesting to roll the study out across other centers afterward. We want to point out that the survey focused on the phenomenon of non-compliance with medical recommendations associated with pharmacotherapy. Research interests require further consideration of the scope of non-compliance with medical recommendations related to a change of lifestyle on the treatment effectiveness of type 2 diabetes.

Furthermore, we are deeply aware of the fact that several outcomes were surrogate values which may not always have an impact on significant patient outcomes. It must be emphasized that the examined patients on the $2-$ $3 \mathrm{~g}$ daily dose of metformin refused polytherapy. The reasons for the decisions were different, including, eg, drug's price or fear of insulin therapy. The results of our study may be used as arguments for intensifying treatment when talking to a diabetic patient.

\section{Conclusions}

Primarily, we confirmed worse metabolic effects of an intensive dose of metformin alone for non-adherence patients with type 2 diabetes versus in combination with insulin for adherence patients. The efficacy of metformin in achieving normoglycemia increased with the addition of insulin to the therapy. The choice to use an intensive dose of metformin only or in combination with insulin is associated with improved glycaemic control, less weight gain, decreased diastolic blood pressure and reduced total 
cholesterol levels. Secondarily, using logistic regression analysis, we proved that increased baseline obesity and increased baseline glycemia were all significantly associated with the likelihood of failing to achieve target levels for HbAlc. Finally, our study shows how many health benefits are lost to patients who, despite systematic diabetes education, do not agree to change their therapy and add a second drug, including insulin. In addition, the results of the conducted research provide valuable scientific evidence for health care policymakers supporting an increase in financial resources allocated to patient education in the field of treatment methods and the consequences of ineffective diabetes treatment due to patient non-adherence.

\section{Abbreviations}

DM, Diabetes Mellitus; FPG, Fasting plasma glucose; HbA1c, glycated haemoglobin; TC, total cholesterol; TG, triglyceride; HDL-C, high density lipoprotein; LDL-C, low density lipoprotein; BMI, body mass index; eGFR, estimated glomerular filtration rate; PDA, Polish Diabetes Association.

\section{Data Sharing Statement}

The dataset generated and analysed in this study is not publicly available but may be obtained from the corresponding author upon a reasonable request.

\section{Ethics Approval}

The study protocol was approved by the Ethics Committee of the Poznan University of Medical Sciences (No. 35/20) an informed, written consent to attend the study protocol was granted by all participants.

\section{Consent for Publication}

Not applicable.

\section{Author Contributions}

All authors made a significant contribution to the work reported, whether that is in the conception, study design, execution, acquisition of data, analysis and interpretation, or in all this areas; took part in drafting, revising or critically reviewing the article; gave final approval of the version to be published; have agreed on the journal to which the article has been submitted; and agreed to be accountable for all aspects of the work.

\section{Funding}

This research did not receive any specific grant from funding agencies in the public, commercial, or not-forprofit sectors.

\section{Disclosure}

The authors reported no conflicts of interest for this work.

\section{References}

1. Menesi FA, Sherif FM, El-Gharadwi M, et al. comparative study of metformin alone, in combination with insulin or metformin plus insulin in presence of simvastatin in libyan diabetic patients. Pharm Pharmacol Int J. 2017;5(2):58-62.

2. American Diabetes Association. Diagnosis and classification of diabetes mellitus. Diabetes Care. 2009;32(Suppl 1):S62-S67. doi: $10.2337 /$ dc09-S062.

3. Weyer C, Hanson RL, Tataranni PA, Bogardus C, Pratley RE. A high fasting plasma insulin concentration predicts type 2 diabetes independent of insulin resistance. Evidence for a pathogenic role of relative hyperinsulinemia. Diabetes. 2000;49:2094-2101.

4. Galicia-Garcia U, Benito-Vicente A, Jebari S, et al. Pathophysiology of Type 2 diabetes mellitus. Int. J. Mol. Sci. 2020;21:6275. doi:10.3390/ijms21176275

5. Hu FB. Globalization of Diabetes: the role of diet, lifestyle and genes. Diabetes Care. 2011;34(6):1249-1257.

6. Oputa RN. Diabetes mellitus: a global epidemic with potential solutions. Afr J Diabetes Med. 2012;20(2):33-35.

7. Olokoba AB, Obateru OA, Olokoba LB. Type 2 diabetes mellitus: a review of current trends. Oman Med J. 2012;27(4):269-273. doi:10.5001/omj.2012.68

8. Kharroubi AT, Darwish HM. Diabetes mellitus: the epidemic of the century. World J Diabetes. 2015;6(6):850-867. doi:10.4239/wjd.v6. i6.850

9. Hundal R, Krssak M, Dufour S, et al. Mechanism by which metformin reduces glucose production in type 2 diabetes. Diabetes. 2000;49 (12):2063-2069.

10. 2021 Guidelines on the management of patients with diabetes. A position of Diabetes Poland. J Diabetes Poland. 2021;10(1). doi:10.5603/DK.2021.0001

11. Rena G, Hardie G, Pearson E. The mechanisms of action of metformin. Diabetologia. 2017;60(9):1577-1585.

12. Gong L, Goswami S, Giacomini KM, Altman RB, Klein TE. Metformin pathways: pharmacokinetics and pharmacodynamics. Pharmacogenet Genomics. 2012;22(11):820-827.

13. DeFronzo RA, Goodman AM. Efficacy of metformin in patients with non-insulin-dependent diabetes mellitus. The Multicenter Metformin Study Group. N Engl J Med. 1995;333:541-549.

14. Margit Solymár M, Ivic I, Pótó L, Hegyi P, Garami A, Hartmann P. Metformin induces significant reduction of body weight, total cholesterol and LDL levels in the elderly - a meta-analysis. PLOS ONE. 2018;26. doi:10.1371/journal.pone.0207947.

15. Wulffele MG, Kooy A, Lehiert P, et al. Combination of insulin and metformin in the treatment of type 2 diabetes. Diabetes Care. 2002;25:2133-2140.

16. Diabetes Prevention Program Research Group. Reduction in the incidence of type 2 diabetes with lifestyle intervention or metformin. N Engl J Med. 2002;346:393-403.

17. Weng J, Li Y, Xu W, et al. Effect of intensive insulin therapy on $\beta$ cell function and glycaemic control in patients with newly diagnosed type 2 diabetes: a multicentre randomised paralel- group trial. Lancet. 2008;371:1753-1760. 
18. Hugtenburg JG, Timmers L, Elders PJM, Vervloet M, van Dijk L. Definitions, variants, and causes of nonadherence with medication: a challenge for tailored interventions. Patient Prefer Adherence. 2013;7:675-682. doi:10.2147/PPA.S29549

19. Vrijens B, De Geest S, Hughes DA, et al. A new taxonomy for describ-ing and defining adherence to medications. $\mathrm{Br} \mathrm{J}$ Clin Pharmacol. 2012;73(5):691-705.

20. Khan AR, Al-Abdul Lateef ZN, Al Aithan MA, Bu-Khamseen MA, Ibrahim I, Khan SA. Factors contributing to non-compliance among diabetics attending primary health centers in the Al Hasa district of Saudi Arabia. J Family Community Med. 2012;19(1):26-32. doi:10.4103/2230-8229.94008

21. Loghman Adham M. Medication noncompliance in patients with chronic disease: issues in dialysis and renal transplantation. $\mathrm{Am}$ J Manag Care. 2003;9:155-171.

22. Hemmingsen B, Christensen LL, Wetterslev J, et al. Comparison of metformin and insulin versus insulin alone for type 2 diabetes: systematic review of randomised clinical trials with meta-analyses and trial sequential analyses. BMJ. 2012;344. doi:10.1136/bmj. e1771.

23. Ambade V, Sharma YV, Somani BL. Methods for estimation of blood glucose: a comparative evaluation. Med J Armed Forces India. 1998;54(2):131-133. doi:10.1016/S0377-1237(17)30502-6

24. Wu Y, Yang X, Wang H, Li Z, Wang T. Evaluation of hemoglobin $A_{1 c}$ measurement from filter paper using high-performance liquid chromatography and immunoturbidimetric assay. Scand $J$ Clin Lab Invest. 2017;77(2):104-108. doi:10.1080/00365 513.2016.1271907

25. McNamara JR, Cohn JS, Wilson PW, Schaefer EJ. Calculated values for low-density lipoprotein cholesterol in the assessment of lipid abnormalities and coronary disease risk. Clin Chem. 1990;36 (1):36-42.

26. Beevers G, Lip GYH, O’Brien E. ABC of hypertension. Blood pressure measurement. Part I-Sphygmomanometry: factors common to all techniques. BMJ. 2001;322(7292):981-985. doi:10.1136/ bmj.322.7292.981

27. Turner RC, Cull CA, Frighi V, Holman RR. Glycemic control with diet, sulfonylurea, metformin, or insulin in patients with type 2 diabetes mellitus. JAMA. 2005-2012;1999(21).

28. DCCT Research Group. The relationship of glycemic exposure (HbA1c) to the risk of development and progression of retinopathy in the Diabetes Control and Complications Trial. Diabetes. 1995;44:968-983.

29. Ohkubo Y. Kishikawa H, Araki E, et al. Intensive insulin therapy prevents the progression of diabetic microvascular complications in Japanese patients with non-insulin-dependent diabetes mellitus: a randomized prospective 6-year study. Diabetes Res Clin Pract. 1995;25:103-117.
30. UKPDS Group. Intensive blood glucose control with sulphonylureas or insulin compared with conventional treatment and risk of complications in patients with type 2 diabetes (UKPDS 33). Lancet. 1998;352:837-853.

31. UKPDS Group. UKPDS 28: a randomised trial of efficacy of early addition of metformin in sulphonyl-urea-treated non-insulin dependent diabetes. Diabetes Care. 1998;21:87-92.

32. Wulffele MG, Kooy A, De Zeeuw D. The effect of metformin on blood pressure, plasma cholesterol and triglycerides in type 2 diabetes mellitus: a systematic review. J Int Med. 2004;256:1-14.

33. Aviles-Santa L, Sinding J, Raskin P. Effects of metformin in patients with poorly controlled insulin-treated type 2 diabetes mellitus. Ann Intern Med. 1999;131(3):182-188.

34. Fonseca V, Gill J, Zhou R, Leahy J. An analysis of early insulin glargine added to metformin with or without sulfonylurea: impact on glycaemic control and hypoglycaemia. Diabetes Obes Metab. 2011;13:814-822.

35. Mourão-Júnior CA, Sá JR, Guedes OMS, Dib SA. Effects of metformin on the glycemic control, lipid profile, and arterial blood pressure of type 2 diabetic patients with metabolic syndrome already on insulin. Braz J Med Biol Res. 2006;39(4):489-494. doi:10.1590/ S0100-879X2006000400009

36. Kay JP, Alemzadeh R, Langley G, Angelo LD, Smith P, Holshouser S. Beneficial effects of metformin in normoglycemic morbidly obese adolescents. Metabolism. 2001;50(12):1457-1461. doi:10.1053/meta.2001.28078

37. Malina SK, Kashya SR. Effects of metformin on weight loss: potential mechanisms. Curr Opin Endocrinol Diabetes Obes. 2014;21:323-329.

38. Giugliano D, De Rosa N, Di Maro G, et al. Metformin Improves glucose, lipid metabolism, and reduces blood pressure in hypertensive, obese women. Diabetes Care. 1993;16(10):1387-1390.

39. Long Z, Huanhuan L, Xiaoxiao W, Yaguang P, Yu T, Liancheng Z. Effects of metformin on blood pressure in nondiabetic patients a meta-analysis of randomized controlled trials. J Hypertens. 2017;35 (1):18-26.

40. Giugliano D, Quatraro A, Consoli G, et al. Metformin for obese, insulin-treated diabetic patients: improvement in glycaemic control and reduction of metabolic risk factors. Eur J Clin Pharmacol. 1993;44:107-112.

41. Khattab M, Khader YS, Al-Khawaldeh A, Ajlouni K. Factors associated with poor glycemic control among patients with Type 2 diabetes. J Diabetes Complications. 2010;24(2):84-89.

42. Drake TC, Hsu FC, Hire D, et al. Factors associated with failure to achieve a glycated haemoglobin target of $<8.0 \%$ in the Action to Control Cardiovascular Risk in Diabetes (ACCORD) trial. Diabetes Obes Metab. 2016;18:92-95. doi:10.1111/dom.12569

Diabetes, Metabolic Syndrome and Obesity: Targets and Therapy

\section{Dovepress}

\section{Publish your work in this journal}

Diabetes, Metabolic Syndrome and Obesity: Targets and Therapy is an international, peer-reviewed open-access journal committed to the rapid publication of the latest laboratory and clinical findings in the fields of diabetes, metabolic syndrome and obesity research. Original research, review, case reports, hypothesis formation, expert opinion and commentaries are all considered for publication. The manuscript management system is completely online and includes a very quick and fair peer-review system, which is all easy to use. Visit http://www.dovepress.com/testimonials.php to read real quotes from published authors. 